\title{
Uji Mukoadhesif Nanopartikel Crude Bromelin dari Perasan Bonggol Nanas Berbasis Hidroksi Propil Selulosa-Sisteamin
}

\author{
Deni Rahmat*, Stella Salim \\ Fakultas Farmasi Universitas Pancasila, Jakarta Selatan, 12640 \\ *Email korespondensi : mangnden78@yahoo.com \\ (Submit 15/03/2019, Revisi 05/09/2019, Diterima 20/12/2019)
}

\begin{abstract}
Abstrak
Hidroksi Propil Selulosa (HPC)-Sisteamin merupakan tiomer kationik hasil modifikasi HPC yang dikonjugasikan dengan gugus sulfidhril dari sisteamin. Tujuan dari penelitian ini adalah untuk membuat nanopartikel berbasis tiomer HPC-Sisteamin dengan sifat mukoadhesif yang baik. Pembuatan nanopartikel berbasis HPC-Sisteamin dilakukan dengan metode gelasi ionik dengan natrium alginat sebagai penggelasi terbaik dengan ukuran partikel $76,47 \mathrm{~nm}$ dan potensial zeta $-24,2 \mathrm{mV}$. Hasil pengujian mukoadhesif menunjukkan bahwa persentase nanopartikel yang tertinggal pada mukus setelah 3 jam pengujian adalah sebesar $3,81 \%$. Berdasarkan analisa data dengan metode Anova satu arah menggunakan Microsoft Excel pada taraf signifikansi 0,01 diperoleh kesimpulan yaitu tidak adanya perbedaan yang bermakna dari hasil pengujian uji mukoadhesif antara tiap jam pengujian.
\end{abstract}

Kata kunci: Mukoadhesif, bromelin, nanopartikel, hidroksi propil selulosa - sisteamin

\section{Outline}

- Pendahuluan

- Metode

- Hasil dan Pembahasan

- Kesimpulan

- Ucapan Terima Kasih

- Daftar Pustaka

\section{Pendahuluan}

Sediaan obat harus bisa melepaskan zat aktif secara cepat agar suatu obat dapat dengan cepat memberikan suatu efek terapi pada tubuh. Selain cepat, dibutuhkan sistem pengantaran obat yang bertarget. Untuk mengatasi masalah tersebut maka dapat dimanfaatkan teknologi nanopartikel. Nanopartikel adalah partikel atau globul pada skala nanometer (10 -1000 nm) yang memiliki sifat fisik yang khas dibandingkan dengan partikel yang berukuran lebih besar, terutama dalam meningkatkan kualitas penghantaran obat. Salah satu pembuatan nanopartikel adalah dengan menggunakan polimer. Pembuatan nanopartikel dengan menggunakan polimer dapat dimanfaatkan untuk sistem penghantaran tertarget, meningkatkan bioavailabilitas, pelepasan obat terkendali, atau melarutkan obat untuk penghantaran sistemik ${ }^{1,2}$. 
Salah satu biopolimer yang sering digunakan sebagai sistem penghantaran obat adalah kitosan. Dari hasil penelitian sebelumnya kitosan dapat digunakan sebagai nanocarrier obat oral tetapi kitosan memiliki keterbatasan antara lain kitosan tidak memiliki sifat penetrasi, mukoadhesif yang baik pada $\mathrm{pH}$ diatas 6,5. Sistem penghantaran obat secara oral dibutuhkan biopolimer yang stabil pada rentang $\mathrm{pH}$ yang luas agar tahan terhadap $\mathrm{pH}$ asam di lambung dan $\mathrm{pH}$ basa di usus sehingga pada penelitian ini digunakan hidroksi propil selulosa (HPC) sebagai polimer yang akan dimodifikasi menjadi HPC-sisteamin untuk menjadi basis nanopartikel ${ }^{3}$.

Pembentukan nanopartikel dapat dilakukan dengan berbagai metode diantaranya metode penguapan pelarut, metode emulsifikasi spontan, metode polimerisasi dan metode gelasi ionik. Dalam penelitian ini untuk uji sifat mukoadhesif nanopartikel HPCsisteamin, metode yang dipilih untuk pembentukan nanopartikel adalah metode gelasi ionik karena polimer yang digunakan merupakan polimer kationik sehingga dapat ditaut silangkan menggunakan crosslinker bermuatan negatif. Selain itu, metode gelasi ionik dipilih karena prosesnya yang sederhana, tidak menggunakan pelarut organik, dan dapat dikontrol dengan mudah proses pembuatannya ${ }^{4}$.

\section{Metode}

\section{A. Bahan}

Hidroksi propil selulosa (HPC) (Sigma Aldrich, Singapore), sodium periodat (Sigma Aldrich, Singapore), etilen glikol (Sigma Aldrich, Singapore), dapar 2-(N-Morpholino) ethanesulfonic acid hydrate (MES) (Sigma Aldrich, Singapore), sisteamin (Sigma Aldrich, Singapore), sodium sianoborohidrid (Sigma Aldrich, Singapore), $\mathrm{NaOH} 1 \mathrm{~N}$, natrium tripolifosfat, dapar fosfat, natrium alginat, $\mathrm{NaOH} 5 \mathrm{~N}$, etanol $96 \%$, dan tween.

\section{B. Metode}

\section{i. Modifikasi HPC}

Sejumlah 1,5 gram HPC dilarutkan dalam $120 \mathrm{ml}$ air suling dan $20 \mathrm{ml}$ etanol $96 \%$ dengan magnetic stirrer sampai homogen (24 jam), kemudian bungkus wadah dengan alumunium foil dan ditambahkan $800 \mathrm{mg}$ sodium periodat yang dilarutkan dalam $10 \mathrm{~mL}$ aquadest. Lalu campuran diaduk dengan menggunakan magnetic stirrer dalam ruangan gelap selama 3 jam. Kemudian ditambahkan etilen glikol sebanyak $200 \mu \mathrm{L}$ dan larutan kembali distirer selama 1 jam. Selanjutnya dilakukan proses pemurnian dengan menggunakan membran dialisis dalam air suling selama 3 hari dan air dialisis diganti tiap 12 jam. Hasil proses pemurnian dikeringkan dengan metode freeze dry, lalu ditimbang 1 gram untuk dilarutkan dalam $40 \mathrm{ml}$ air. Dan ditambahkan $1 \mathrm{gram}$ dapar MES dan 1 gram sisteamin. Kemudian keasaman diatur pada $\mathrm{pH} 5$ dan ditambahkan dengan air hingga volume $50 \mathrm{ml}$. Campuran diaduk selama 3 jam kemudian ditambahkan 4 gram sodium sianoborohidrid dan pengadukan dilanjutkan selama 3 hari. Lalu hasil reaksi dimurnikan dengan metode dialisis dengan menggunakan dialisis tube dalam air suling selama 3 hari dan air dialisis diganti tiap 12 jam. Lalu hasil dialisis kembali diserbukkan dengan menggunakan metode freeze drying ${ }^{5}$.

\section{ii. Formulasi pembentukan nanopartikel berbasis HPC-Sisteamin}

Modifikasi HPC Hidroksi propil selulosa - sisteamin dan dilakukan pengenceran dengan air hingga konsentrasi $0,2 \%$ kemudian diaduk dengan menggunakan magnetic stirrer selama 30 menit. Setelah itu ditambahkan tween $10 \%$ sebanyak $1 \%$ dari larutan tiomer 
HPC-sisteamin kemudian diaduk dengan menggunakan magnetic stirrer selama 30 menit. Lalu larutan tersebut diteteskan crosslinker tetes demi tetes hingga terbentuk nanopartikel sesuai dengan Tabel 1.

Tabel 1. Formulasi nanopartikel HPC-sisteamin

\begin{tabular}{|l|c|c|c|}
\multicolumn{1}{|c|}{ Bahan } & \multicolumn{3}{|c|}{ Formula } \\
\hline HPC-sisteamin (b/v) & I & II & III \\
\hline Tween 10\% (v/v) & 0,2 & 0,2 & 0,2 \\
\hline Natrium tripolifosfat (b/v) & 1 & 1 & 1 \\
\hline Natrium alginat (b/v) & 0,2 & - & - \\
\hline Dapar fosfat (b/v) & - & 0,2 & - \\
\hline
\end{tabular}

iii. Pengujian mukoadhesif dari serbuk kering nanopartikel

Membran usus direkatkan pada pipa peristaltik dengan sudut $45^{\circ}$ dan pada suhu $37^{\circ} \mathrm{C}$. Membran usus dilembabkan selama 5 menit terlebih dahulu. Selanjutnya $15 \mathrm{mg}$ dari serbuk kering nanopartikel yang telah mengandung FDA (fluorescein diacetate) ditaburkan pada usus dan dilanjutkan dengan dialiri dengan dapar fosfat $\mathrm{pH} 6,8,37^{\circ} \mathrm{C}$, dengan kecepatan alir $1 \mathrm{~mL} / \mathrm{min}$. Lalu membran di inkubasi dalam $25 \mathrm{~mL} \mathrm{NaOH} 5 \mathrm{M}$ selama 20 menit pada suhu $37^{\circ} \mathrm{C}$. Dan dihitung kadarnya menggunakan spektrofluorometer ${ }^{6}$.

\section{Hasil dan Pembahasan}

\section{A. Hasil}

Pada penelitian ini digunakan polimer yang bersifat kationik yaitu hidroksi propil selulosa (HPC). Lalu Polimer HPC dimodifikasi menjadi tiomer HPC-sisteamin dengan menambahkan ligan sisteamin untuk menambahkan gugus sulfhidril pada polimer HPC dengan reaksi reduksi aminasi ${ }^{5}$.

Pembuatan nanopartikel dilakukan dengan cara menambahkan crosslinker yang memiliki polianion seperti natrium tripolifosfat (NaTPP) dengan polianion tripolifosfat, natrium alginat dengan polianion karboksilat dan dapar fosfat dengan anion fosfat kedalam larutan tiomer HPC-sisteamin. Pada proses pembuatan nanopartikel, tiomer HPC-sisteamin diencerkan dengan air hingga konsentrasi 0,2\%. Pengenceran dilakukan menggunakan air karena tiomer HPC-sisteamin larut dalam air. NaTPP yang merupakan polianion seharusnya menjadi crosslinker terbaik dalam pembuatan nanopartikel dibandingkan dengan dapar fosfat dan natrium alginat karena memiliki lebih banyak anion. Hasil optimasi menunjukkan bahwa zat penstabil untuk pembuatan nanopartikel berbasis HPC-sisteamin yang lebih baik adalah tween 80 10\%. Tween 80 dengan konsetrasi $10 \%$ lebih baik dibandingkan dengan tween 80 pekat karena tween 80 10\% lebih encer sehingga lebih mudah terdispersi secara merata dan lebih baik dalam melindungi nanopartikel yang telah terbentuk terhadap agregasi. Hasil uji pemeriksaan ukuran partikel berdasarkan Tabel 2 maka dengan crosslinker natrium alginat memiliki ukuran partikel 76,47 nm dengan indeks polidispersitas (pdl) 0,351. Sedangkan dengan crosslinker dapar fosfat memiliki ukuran partikel sebesar 48,56 nm dengan pdl 0,402. Distribusi ukuran partikel dinyatakan dalam pdl. Rentang pdl berada antara 0 sampai dengan 1 . Semakin mendekati 0 maka sampel lebih homogen dan seragam ukuran partikelnya. Hal ini menyatakan bahwa nanosuspensi dengan 
crosslinker natrium alginat lebih terdispersi secara homogen dibandingkan dapar fosfat. Nanosuspensi dengan crosslinker natrium alginat diperoleh potensial zeta sebesar 24,2 sedangkan dengan crosslinker dapar fosfat diperoleh potensial zeta sebesar -7,34. Nanosuspensi dengan crosslinker natrium alginat bermuatan lebih negatif karena crosslinker natrium alginat memiliki banyak polianion. Karena dari hasil pengujian ukuran partikel dan potensial zeta diketahui bahwa nanopartikel dengan crosslinker natrium alginat adalah yang paling baik. Nanopartikel yang digunakan untuk melakukan pengujian mukoadhesif adalah sebanyak $15 \mathrm{mg}$. Lalu pengujian mukoadhesif dilakukan sebanyak 3 kali. Uji mukoadhesif dilakukan selama 1 jam, 2 jam, 3 jam dan dengan menggunakan peristaltic pump untuk mengalirkan medium dapar fosfat $\mathrm{pH} 6,8$. Lalu setelah waktu pengujian dilakukan pengukuran fluorosensi sesuai yang ditunjukkan Tabel 3 untuk mengetahui jumlah FDA dari nanopartikel HPC-sisteamin yang masih menempel pada mukosa usus ${ }^{6}$.

Tabel 2. Hasil pengujian ukuran partikel dan zeta potensial nanopartikel HPC-Sisteamin

\begin{tabular}{|c|c|c|}
\hline Crosslinker & \multicolumn{2}{|c|}{ Pengujian } \\
\hline Natrium Alginat & Rata-Rata Ukuran Partikel & Rata-Rata Zeta Potensial \\
\hline Dapar Fosfat & $76,47 \mathrm{~nm}$ & $-24,2 \mathrm{mV}$ \\
\hline
\end{tabular}

Tabel 3. Hasil fluorosensi nanopartikel Uji Mukoadhesif

\begin{tabular}{|c|c|c|c|}
\hline \multirow{2}{*}{ Jam ke- } & \multicolumn{3}{|c|}{ Fluorosensi } \\
\hline 1 & 1 & 2 & 3 \\
\hline 2 & 5921 & 6266 & 4649 \\
\hline 3 & 4518 & 4841 & 4304 \\
\hline
\end{tabular}

Dari hasil konversi nilai fluorosensi nanopartikel ke jumlah nanopartikel yang menempel pada mukosa berdasarkan kurva kalibrasi FDA maka didapatkan hasil bahwa jumlah nanopartikel rata-rata yang masih menempel pada mukosa usus babi setelah dilakukan pengujian selama 1 jam sebesar 5,14 \pm 0,60\%, 2 jam sebesar $4,25 \pm 0,19 \%$ dan selama 3 jam sebesar $3,81 \pm 0,49 \%$. Semakin besar kadar FDA yang terukur maka semakin banyak pula nanopartikel yang dapat menempel pada mukosa saluran cerna, nanopartikel juga dapat diabsorpsi dengan lebih baik yang akan mengakibatkan indeks terapi akan tercapai. Dapat dilihat dari penurunan kadar FDA yang tidak terlalu drastis pada waktu 1 jam, 2 jam dan 3 jam, dimana penurunannya hanya kurang lebih $1 \%$ perjam. Pada uji mukoadhesif HPC-Sisteamin diperoleh bahwa setelah pembilasan selama 3 jam, tersisa FDA sebanyak 3\%, dan jika setiap jam terjadi penurunan kadar FDA sebesar 1\%, maka diperkirakan FDA akan habis terbilas setelah 6 jam. Kadar nanopartikel yang didapatkan kecil dapat diakibatkan karena kondisi mukus dari usus babi yang digunakan terlalu encer sehingga mukus dan sampel yang ditabur pada mukus dapat lepas dari usus babi. 


\section{B. Pembahasan}

Cara yang digunakan untuk membuat nanopartikel pada penelitian ini adalah dengan menggunakan metode gelasi ionik. Gelasi ionik adalah metode pembuatan nanopartikel dengan terjadinya kompleksasi polielektrolit antara elektrolit yang bermuatan positif dan bermuatan negatif. Hal ini dapat dilihat pada mekanisme pembentukan nanopartikel kitosan dengan metode ini didasarkan pada interaksi elektostatik antara grup amina dari kitosan dan grup bermuatan negatif polianion seperti tripolifosfat (TPP) akibat kompleksasi antara muatan yang berbeda, kitosan mengalami gelasi ionik dan presipitasi membentuk partikel seperti bola. Sehingga nanopartikel dapat terbentuk secara spontan akibat pengadukan mekanis pada suhu kamar?

Hasil optimasi menunjukan bahwa pembentukan nanopartikel terbaik adalah menggunakan tiomer HPC-sisteamin 0,2\% (10 mL) dengan penggelasi $6 \mathrm{~mL}$ dapar fosfat dan $6 \mathrm{~mL}$ natrium alginat, baik dalam pelarut air maupun asam asetat glasial 8 . Walaupun pembentukan nanopartikel dengan crosslinker dapar fosfat dan natrium alginat menghasilkan kekeruhan yang baik, namun memiliki kestabilan yang kurang baik. Mekanisme Tween 80 dalam melindungi nanopartikel dari agregasi adalah dengan membentuk halangan sterik yang membungkus nanopartikel sehingga mencegah nanopartikel beragregasi ${ }^{9}$.

Nanopartikel yang memiliki zeta potensial yang (+/-) $25 \mathrm{mV}$ maka akan diperoleh nanosuspensi yang lebih stabil ${ }^{7}$. Sehingga dapat dilihat bahwa nanosuspensi dengan crosslinker natrium alginat lebih stabil dari pada nanosuspensi dengan crosslinker dapar fosfat. Nanosuspensi dengan crosslinker dapar fosfat maka akan cenderung lebih mudah beragregasi dan mengalami pengendapan dari pada nanosuspensi dengan crosslinker natrium alginat. Mekanisme mukoadhesif dapat terjadi karena nanopartikel memiliki gugus sulfhidril yang dapat membentuk ikatan disulfida dengan gugus sulfhidril yang terdapat pada mukosa saluran cerna ${ }^{5}$.

\section{Kesimpulan}

Nanopartikel HPC-Sisteamin dapat dibuat nanopartikel yang baik menggunakan crosslinker natrium alginat $0,2 \%$ dengan metode gelasi ionik. Nanopartikel berbasis Tiomer HPC-Sisteamin memiliki sifat mukoadhesif pada mukosa usus saluran cerna dengan persentase nanopartikel sebesar $3,81 \%$ setelah 3 jam pengujian.

\section{Ucapan Terima Kasih}

Ucapan terima kasih ditujukan kepada Ristek DIKTI atas dana yang diberikan dalam skema Hibah Kompetensi.

\section{Daftar Pustaka}

1. Martin R, et al. Perkembangan Teknologi Nanopartikel Sebagai Sistem Penghantaran Obat. Majalah Farmaseutik, 2012;8(1):133-135.

2. Napsah R, Wahyuningsih I. Preparasi Nanopartikel Kitosan-TPP/Ekstrak Etanol Daging Buah Mahkota Dewa (Phaleriamacrocarpa (Scheff) Boerl) dengan Metode Gelasi lonik. Jurnal Farmasi Sains dan Komunitas. 2014;11(1):7-8. 
3. Trivedi MK, et al. Influence of Biofield Treatment on Physicochemical Properties of Hydroxyethyl Cellulose and Hydroxypropyl Cellulose. J Mol Pharm Org Process Res. 2015;3(2):1-2.

4. Mardliyati E, Muttaqien SEI, Setyawati DR. Sintesis Nanopartikel KitosanTrypolyphosphate dengan Metode Gelasi lonik: Pengaruh Konsentrasi dan Rasio Volume terhadap Karakteristik Partikel. Prosiding Pertemuan IImiah IImu Pengetahuan dan Teknologi Bahan; 2012.p.90-91.

5. Rahmat D, et al. Design and Synthesis of a Novel Cationic Thiolated Polymer. International Journal of Pharmaceutics. 2011;411:10-12.

6. Adrian. Formulasi dan Karakterisasi Nanopartikel Atenolol menggunakan Polimer Kitosan-Alginat dengan Metode Gelasi lonotropik. Jakarta: Fakultas Farmasi Universitas Pancasila. 2014;8:16-19.

7. Nadia L, Suptijah P, Ibrahim B. Produksi dan Karakterisasi Nano Kitosan dari Cangkang Udang Windu dengan Metode Gelasi lonik. JPHPI. 2014;17(2):120121.

8. Kauper P, Forrest M. Chitosan-Based Nanoparticle by Ionotropic Gelation. Switzerland. 2006:1.

9. $\mathrm{Li}$ et al. Large-Scale Synthesis and Self-Organization of Silver Nanoparticle with Tween 80 as a Reductant and Stabilizer. Nano Express. 2012;7(1):612. 